\title{
A three-year longitudinal study of affective temperaments and risk for psychopathology
}

By: Daniella P. DeGeorge, Molly A. Walsh, Neus Barrantes-Vidal, Thomas R. Kwapil

DeGeorge, D.P., Walsh, M.A., Barrantes-Vidal, N., \& Kwapil, T.R. (2014). A three-year longitudinal study of affective temperaments and risk for psychopathology. Journal of Affective Disorders, 164, 94-100.

Made available courtesy of Elsevier: http://dx.doi.org/10.1016/j.jad.2014.04.006

\section{(c) (1) () \\ EY NG ND This work is licensed under a Creative Commons Attribution- NonCommercial-NoDerivatives 4.0 International License.}

\begin{abstract}
:
Background

Affective temperaments are presumed to underlie bipolar psychopathology. The TEMPS-A has been widely used to assess affective temperaments in clinical and non-clinical samples. Crosssectional research supports the association of affective temperaments and mood psychopathology; however, longitudinal research examining risk for the development of bipolar disorders is lacking. The present study examined the predictive validity of affective temperaments, using the TEMPS-A, at a three-year follow-up assessment.
\end{abstract}

Methods

The study interviewed 112 participants (77\% of the original sample) at a three-year follow-up of 145 non-clinically ascertained young adults psychometrically at-risk for bipolar disorders, who previously took part in a cross-sectional examination of affective temperaments and mood psychopathology.

Results

At the reassessment, 29 participants (26\%) met criteria for bipolar spectrum disorders, including 13 participants who transitioned into disorders during the follow-up period (14\% of the originally undiagnosed sample). Cyclothymic/irritable and hyperthymic temperaments predicted both total cases and new cases of bipolar spectrum disorders at the follow-up.

Cyclothymic/irritable temperament was associated with more severe outcomes, including DSMIV-TR bipolar disorders, bipolar spectrum psychopathology, major depressive episodes, and substance use disorders. Hyperthymic temperament was associated with bipolar spectrum psychopathology and hypomania, whereas dysthymic temperament was generally unassociated with psychopathology and impairment.

Limitations 
The present sample of young adults is still young relative to the age of onset of mood psychopathology.

\section{Conclusions}

These results provide the first evidence of the predictive validity of affective temperaments regarding risk for the development of bipolar psychopathology. Affective temperaments provide a useful construct for understanding bipolar psychopathology.

Keywords: Affective temperament | TEMPS-A | Bipolar spectrum | Bipolar disorder

\section{Article:}

\section{Introduction}

Traditional epidemiological studies estimate the prevalence of bipolar disorders to be approximately 1\% of the population (Akiskal et al., 2000 and Judd and Akiskal, 2003). Bipolar disorders are a leading public health concern that result in severe impairment, enormous health costs, and marked risk of premature death. Furthermore, bipolar disorders have a negative effect on psychosocial functioning resulting in increased interpersonal problems, legal issues, and homelessness (Judd et al., 2005). Bipolar disorders are also associated with increased substance use/abuse and premature death, most often due to suicide (Perroud et al., 2011). It is estimated that individuals with bipolar disorders have approximately double the mortality rate and a 10 times higher suicide rate in comparison to the general population (Ösby et al., 2001).

There appears to be a broader spectrum of bipolar psychopathology that is not captured by traditional categorical diagnoses. Recent research has provided support for understanding bipolar disorders across a continuum of bipolar spectrum psychopathology (Angst et al., 2003, Ghaemi et al., 2002 and Walsh et al., 2012b). This spectrum of psychopathology incorporates subthreshold symptoms that can cause marked impairment in one's daily functioning. Current studies suggest that 4-5\% of the general population may fall on this broader bipolar spectrum, which is markedly higher than traditional prevalence estimates (Akiskal et al., 2000).

There have been two approaches to considering a broader spectrum of bipolar psychopathology. The first has involved expanding the number of categorical diagnoses set forth by the diagnostic nomenclature. For example, building on the DSM-IV-TR (American Psychiatric Association, 2000), Akiskal (2004) proposed the addition of bipolar II 1/2, bipolar III, and bipolar IV disorders. Bipolar II $1 / 2$ is characterized by major depressive episodes superimposed on cyclothymic temperament, whereas bipolar III involves repeated major depressive episodes in addition to hypomania occurring solely in association with use of antidepressant medications or other somatic treatment. Lastly, bipolar IV is characterized by major depression superimposed on hyperthymic temperament. Note that other authors have suggested six or more variations of bipolar disorders (Akiskal and Pinto, 1999 and Klerman, 1987). These formulations expand the diagnosis of bipolar disorders; however, they are limited in that they still employ a categorical model that may not adequately capture the full spectrum of bipolar psychopathology or its dimensional characteristics. 
The second approach to capturing bipolar psychopathology has involved the use of dimensional traits or temperaments. Building upon the framework established by Kraeplin (1899/1921), Akiskal and Mallya (1987) operationalized four affective temperaments that range from subclinical expressions to severe clinical impairment. These include cyclothymic, irritable, dysthymic, and hyperthymic temperaments. In contrast to categorical bipolar disorders, affective temperaments are continuous, trait-like expressions of affect that are believed to underlie mood psychopathology (Akiskal et al., 2005a). These temperaments tend to have an early onset, are enduring, and for some people are relatively non-impairing. However, affective temperaments also presumably convey risk for developing mood disorders.

Cyclothymic temperament is characterized by chronic cycling between high and low moods lasting a few days each (Akiskal et al., 2000). This biphasic shift in mood is also accompanied by other cyclical patterns including over-confidence alternating with shaky self-esteem, heightened creativity with mental discord, and people-seeking with introversion/social avoidance. Irritable temperament involves being ill-tempered, impulsive, and reactive to aversive events with negative affect. Irritable temperament is often associated with cyclothymic temperament as the two share considerable conceptual and empirical overlap. Akiskal et al. (1979) also suggested overlap between borderline personality and irritable temperament, as both involve rapid shifts in mood and erratic behavior.

Dysthymic temperament is operationalized as being consistently gloomy, pessimistic, selfcritical, and derogatory of one's self, in conjunction with a preoccupation with failure and inadequacy in life. In addition, dysthymic temperament includes constant brooding and worrying, skepticism, and an overall indecisiveness (Akiskal et al., 2005a). Kraeplin (1899/1921) provided especially rich descriptions of patients with depressive temperament, describing them as "characterized by permanent gloomy emotional stress in all the experiences in life" (p. 119).

In contrast, hyperthymic temperament can involve adaptive characteristics including cheerfulness, increased energy, people-seeking, and interpersonal warmth. However, hyperthymic temperament also involves problematic features such as recklessness, overconfidence, over-involvement, along with grandiose thoughts and ideas (Akiskal et al., 2000). These maladaptive characteristics can be detrimental to daily functioning and lead to marked impairment in interpersonal relationships, health, and professional well-being (Akiskal et al., 2005a).

The Temperament Evaluation of Memphis, Pisa, Paris, and San Diego-Autoquestionnaire (TEMPS-A; Akiskal et al., 2005a) is a self-report measure designed to assess affective temperaments. Specifically, it assesses affective, cognitive, social, circadian, emotional, and psychomotor features of affective temperaments (Akiskal et al., 2005b). Akiskal et al. (2005a) examined the psychometric properties of the TEMPS-A in a clinical sample and reported testretest reliability ranging from .58 to .70 over a 6 to 12-month period. Additionally, Cronbach's alpha coefficients ranged from .76 to .88 . Numerous studies have validated the TEMPS-A as a measure of affective temperaments in both clinical (Di Florio et al., 2010, Evans et al., 2005 and Mendlowicz et al., 2005) and nonclinical settings (Borkowska et al., 2010, Hinic et al., 2013, Rózsa et al., 2008 and Signoretta et al., 2005). 
Recent studies have provided evidence of the association of affective temperaments with mood psychopathology and impairment. Nilsson et al. (2012) examined affective temperaments and functional impairment in a clinical sample of bipolar patients over 24 months. Cyclothymic temperament was significantly associated with overall functional impairment, including dysfunction in home management, leisure activities, and social activities. These findings support the notion that affective temperaments are relatively stable and can cause impairment throughout and not exclusively during mood episodes.

Recent cross-sectional research has also indicated that affective temperaments are associated with distinct patterns of psychopathology and impairment. Walsh et al. (2012a) examined affective temperaments in a non-clinically ascertained sample of young adults at risk for bipolar psychopathology. Cyclothymic, irritable, and hyperthymic temperaments were associated with DSM-IV-TR bipolar disorders and broader bipolar spectrum disorders along with hypomania and major depressive episodes. Contrastingly, dysthymic temperament was generally unassociated with psychopathology and impairment. Specifically, cyclothymic/irritable temperament was associated with more deleterious outcomes such as DSM-IV-TR bipolar disorders, broader bipolar spectrum disorders, and impaired functioning. Hyperthymic temperament was associated with broader bipolar spectrum disorders and hypomania, yet was positively associated with psychosocial functioning suggesting that it may possess some adaptive qualities. These results offer evidence for cyclothymic/irritable and hyperthymic temperaments conveying risk for bipolar spectrum psychopathology. However, to our knowledge there have not been any longitudinal studies examining risk for bipolar psychopathology in non-clinically identified samples.

Goals and hypotheses

The present study examined the association of affective temperaments with bipolar psychopathology and impairment in a three-year follow-up assessment of the sample initially reported in Walsh et al. (2012a) and Walsh et al. (2013). This was the first study to our knowledge to examine longitudinal associations of hyperthymic, dysthymic, cyclothymic, and irritable temperaments with psychopathology and impairment in a non-clinically ascertained sample of young adults. Specifically, it was hypothesized that cyclothymic and irritable temperament would be associated with DSM-IV-TR bipolar disorders, bipolar spectrum disorders, unipolar depression, borderline personality disorder symptoms, impaired functioning, and substance use/abuse. Hyperthymic temperament was expected to be positively associated with DSM-IV-TR bipolar disorders, bipolar spectrum disorders, history of hypomania, and psychosocial functioning. Finally, dysthymic temperament was hypothesized to be positively associated with unipolar depression and impaired psychosocial functioning.

\section{Methods}

Participants

Initial assessment 
All participants completed a cross-sectional assessment (see Walsh et al., 2012a). Participants were recruited from approximately 1200 students enrolled in introductory psychology courses at the University of North Carolina at Greensboro (UNCG) who completed self-report questionnaires for course credit as part of a departmental mass-screening. A total of 191 students were invited to participate in a cross-sectional interview and experience sampling study. Specifically, all of the mass-screening participants who scored at least 1.5 SD above the mean on the Hypomanic Personality Scale (HPS; Eckblad and Chapman, 1986) and a comparable sample of participants who scored less than 1.5 SD above the mean were invited to participate. A total of 147 participants took part in the study. Two participants were dropped from the final study due to invalid questionnaire measures.

Three-year follow-up assessment

All 145 participants who completed the initial assessment were invited to participate in the follow-up. One hundred twelve participants ( $77 \%$ of the original sample) were reassessed, including 76 women and 36 men; mean age $=22.6$ years, $\mathrm{SD}=2.6$ years. The mean interval between assessments was 3.1 years ( $\mathrm{SD}=0.5$ years, range 1.7 to 4.8 years). The sample was $64 \%$ Caucasian, 18\% African American, 5\% Hispanic, 5\% Asian/Pacific Islander, 4\% other, and 5\% unspecified. There were no significant differences between the total, follow-up, and nonfollowed samples with respect to affective temperament scores, bipolar spectrum disorders, psychosocial functioning, or demographic characteristics as measured at the initial assessment (see Table 1). Note that all participants provided informed consent. The study was approved by the UNCG Institutional Review Board and conformed to the Helsinki Declaration as revised in 1989. Participants were paid for their participation.

\begin{tabular}{|c|c|c|c|}
\hline Initial assessment criterion & $\begin{array}{l}\text { Total sample } \\
(n=145)\end{array}$ & $\begin{array}{l}\text { Follow-up } \\
(n=112)\end{array}$ & $\begin{array}{l}\text { Non-followed } \\
(n=33)\end{array}$ \\
\hline \multicolumn{4}{|l|}{ Affective temperament score $(M, S D)$} \\
\hline Hyperthymic & $8.6(2.8)$ & $8.8(2.8)$ & $8.2(3.0)$ \\
\hline Dysthymic & $4.6(2.1)$ & $4.7(2.1)$ & $4.4(2.1)$ \\
\hline Cyclothymic & $4.6(3.9)$ & $4.8(4.0)$ & $4.0(3.8)$ \\
\hline Irritable & $1.6(1.9)$ & $1.6(2.0)$ & $1.4(1.7)$ \\
\hline Bipolar spectrum disorder (no. and \%) & $22(15.2 \%)$ & $18(16.1 \%)$ & $4(12.1 \%)$ \\
\hline $\begin{array}{l}\text { GAF-Psychosocial functioning }(M \text {, } \\
S D)\end{array}$ & $76.1(12.8)$ & $75.9(12.7)$ & $77.0(13.1)$ \\
\hline Female participants (\%) & $69.0 \%$ & $67.9 \%$ & $72.7 \%$ \\
\hline Age $(M, S D)$ & $19.5(2.3)$ & $19.5(2.5)$ & $19.5(1.5)$ \\
\hline Caucasian $(\%)$ & $64.8 \%$ & $64.3 \%$ & $66.7 \%$ \\
\hline Afric an Americ an (\%) & $15.9 \%$ & $17.9 \%$ & $9.1 \%$ \\
\hline Hispanic (\%) & $4.1 \%$ & $4.5 \%$ & $3.0 \%$ \\
\hline Asian (\%) & $4.1 \%$ & $4.5 \%$ & $3.0 \%$ \\
\hline Other $(\%)$ & $4.1 \%$ & $3.6 \%$ & $6.1 \%$ \\
\hline Unspecified (\%) & $6.9 \%$ & $5.4 \%$ & $12.1 \%$ \\
\hline
\end{tabular}


Table 1. Comparisons of ratings and demographic information from the initial assessment, for the total, followed-up, and non-followed samples.

Materials and procedures

Measures at the initial assessment

Mass-screening participants completed a demographic questionnaire, the HPS, as well as additional questionnaires not included in the present study. The HPS consists of 48 true-false items that assess mild, trait-like manic functioning that identify risk for bipolar disorder.

All participants completed a structured interview (see Walsh et al., 2012a) that assessed DSMIV-TR mood disorders, broader bipolar spectrum psychopathology, borderline personality traits, alcohol and drug use/abuse, family history of psychopathology, and past history of treatment for psychopathology. Participants completed self-report questionnaires, including the 50-item research version of the TEMPS-A and took part in a week-long experience sampling methodology (ESM) assessment (see Walsh et al., 2013).

Measures at the follow-up assessment

Reassessed participants completed a structured interview comparable to the one administered at the initial assessment. The Structured Clinical Interview for DSM-IV (SCID-I; First et al., 1995) assessed past and current DSM-IV-TR mood disorders. Broad bipolar spectrum disorders were diagnosed using the criteria reported in Akiskal (2004). The SCID-I interview was appropriate for determining diagnoses of bipolar II $1 / 2$ (history of depression superimposed on cyclothymic temperament) and III (history of depression and antidepressant-induced hypomania). Using criteria in Akiskal (2004), participants were interviewed for hyperthymic temperament to determine diagnoses of bipolar IV (history of depression superimposed on hyperthymic temperament). Substance use disorders were assessed using the SCID-I and the scoring system reported in Kwapil (1996) to provide quantitative ratings of substance use/abuse. Borderline personality traits were assessed using the International Personality Disorder Examination (IPDE; Loranger et al., 1994). The global assessment of functioning (GAF; American Psychiatric Association, 2000) was used to measure current functioning. A brief measure of grandiosity was also included in the interview in which participants used a 6-point Likert scale to rate the likelihood that they would be featured on the cover of a magazine or become famous, whether they believed themselves to be odd or different compared to their peers, as well as their levels of creativity and ambition. Participants were also asked whether they regarded themselves as a leader or a follower. Interviews were conducted by a licensed clinical psychologist, an advanced graduate student in clinical psychology, and an advanced undergraduate psychology researcher. All interviews were tape-recorded and lasted approximately 1-2 h. Note that a majority of the interviews $(84 \%)$ were completed in person. However, $16 \%$ of the interviews were completed via telephone or Skype.

In addition to completing the structured interview, participants completed two brief self-report questionnaires. To further examine the association of affective temperaments with impulsivity, participants completed the Impulse-Nonconformity Scale (INS; Chapman et al., 1984), a 51 item 
true-false self-report questionnaire that measures stable traits such as lack of empathy, lack of respect for social norms, and lack of concern for others' rights and feelings, and the UPPS Impulsivity Scale (Whiteside et al., 2005), a 46 item self-report questionnaire that measures four facets of impulsive behavior: negative urgency (reckless behavior during a state of negative affect), lack of premeditation (little consideration for consequence of actions), lack of perseverance (inability to stay focused on current activity), and sensation seeking (pleasure in new activities despite potential risk).

\section{Results}

Binary logistic regressions were computed to examine the association of affective temperaments with dichotomous measures (e.g. diagnoses of psychopathology). Linear regressions were computed to examine the relation of affective temperaments with continuous measures of psychopathology and impairment. Consistent with Walsh et al. (2012a), cyclothymic and irritable temperaments scores were combined into a single temperament index score. In each analysis, the three affective temperaments (hyperthymic, dysthymic, and cyclothymic/irritable) were entered into the regression analyses simultaneously so that the unique effects of each temperament were assessed (over-and-above the effects of the other temperaments).

A total of 29 (26\%) of the 112 reassessed participants met criteria for a bipolar spectrum disorder at the follow-up. Twelve participants (11\%) qualified for a DSM-IV-TR bipolar disorder and 17 qualified for a non-DSM bipolar disorder. The 12 participants who met criteria for DSM-IV-TR bipolar disorders included two with bipolar I disorder, seven with bipolar II disorder, and three with bipolar NOS disorder. All participants classified as bipolar NOS exhibited current hyperthymic temperament and history of hypomania. Among the 17 participants diagnosed with non-DSM bipolar disorders at the follow-up, 12 qualified for bipolar IV disorder and five qualified for "other bipolar spectrum disorder." The five participants classified as "other bipolar spectrum disorder" included two participants with current hyperthymic temperament and history of subthreshold depression, one participant with history of major depression and subthreshold hypomania, one participant with past hypomania and hyperthymic temperament, and one participant with past hypomania. Note that 13 participants without bipolar diagnoses at the initial assessment transitioned into disorders during the follow-up period (14\% of the originally undiagnosed sample).

Table 2 presents the prediction of mood psychopathology and substance use/abuse by affective temperament scores at the follow-up assessment. Cyclothymic/irritable temperament predicted DSM-IV-TR bipolar disorders, broad bipolar spectrum disorders, hypomanic episodes or hyperthymic temperament, and major depressive episodes, but not unipolar major depressive disorder. Cyclothymic/irritable temperament also predicted new cases of broader bipolar spectrum disorders that developed since the initial assessment $(\mathrm{OR}=2.99, \mathrm{CI}=1.20-7.46, \mathrm{p}<.05)$, but not new cases of DSM-IV-TR bipolar disorders ( $\mathrm{OR}=.532, \mathrm{CI}=.08-3.45)$. Fig. 1 displays the percentage of DSM-IV-TR bipolar disorders and broad bipolar spectrum disorders at the followup assessment by quartiles of cyclothymic/irritable temperament scores at the initial assessment. Cyclothymic/irritable temperament also predicted diagnoses of substance use disorders.

Hyperthymic temperament predicted bipolar spectrum disorders and episodes of hypomania or hyperthymic temperament at the follow-up in the total sample; however, it did not predict DSM- 
IV-TR bipolar disorders. Hyperthymic temperament predicted new cases of broader bipolar spectrum disorders at the follow-up assessment ( $\mathrm{OR}=1.52, \mathrm{CI}=1.09-2.13, \mathrm{p}<.05)$, but not new cases of DSM-IV-TR bipolar disorders $(\mathrm{OR}=1.39, \mathrm{CI}=.83-2.32)$. Additionally, hyperthymic temperament predicted a decreased likelihood of unipolar major depressive disorder, suggesting that high hyperthymic temperament was specifically associated with bipolar, but not unipolar, mood psychopathology. Surprisingly, dysthymic temperament was not significantly associated with any diagnoses.

\begin{tabular}{|c|c|c|c|c|c|c|c|}
\hline \multirow{2}{*}{ Criterion } & \multirow{2}{*}{$\begin{array}{l}\% \text { of } \\
\text { sample }\end{array}$} & \multicolumn{2}{|c|}{ Hyperthymic } & \multicolumn{2}{|c|}{ Dysthymic } & \multicolumn{2}{|c|}{ Cyclothymic/irritable } \\
\hline & & OR & $95 \% \mathrm{Cl}$ & OR & $95 \% \mathrm{Cl}$ & OR & $95 \% \mathrm{Cl}$ \\
\hline DSM bipolar disorder & $11 \%$ & 1.27 & $.96-1.67$ & 1.15 & $\begin{array}{l}.79- \\
1.68\end{array}$ & $2.29^{+}$ & $1.18-4.46$ \\
\hline Bipolar spectrum disorder & $26 \%$ & $1.61^{* * *}$ & $\begin{array}{l}1.24- \\
2.08\end{array}$ & 1.08 & $\begin{array}{l}.81- \\
1.45\end{array}$ & $3.23^{+* *+}$ & $1.69-6.17$ \\
\hline $\begin{array}{l}\text { DSM major depressive } \\
\text { episode }\end{array}$ & $44 \%$ & .96 & $.81-1.14$ & 1.01 & $\begin{array}{l}.80- \\
1.29\end{array}$ & $2.13^{+*}$ & $1.27-3.60$ \\
\hline $\begin{array}{l}\text { DSM major depressive } \\
\text { disorder }\end{array}$ & $22 \%$ & $.72^{* *}$ & $.58-.88$ & .86 & $\begin{array}{l}.65- \\
1.13\end{array}$ & 1.20 & $.71-2.01$ \\
\hline Hypomania or hyperthymia & $34 \%$ & $1.98^{+*+}$ & $\begin{array}{l}1.48- \\
2.66\end{array}$ & 1.04 & $\begin{array}{l}.78- \\
1.40\end{array}$ & $3.43^{+*+}$ & $1.73-6.79$ \\
\hline $\begin{array}{l}\text { Alcohol abuse or } \\
\text { dependence }\end{array}$ & $13 \%$ & 1.24 & $.95-1.62$ & .79 & $\begin{array}{l}.54- \\
1.15\end{array}$ & $2.63^{\text {t* }}$ & $1.36-5.08$ \\
\hline Drug abuse or dependence & $18 \%$ & 1.17 & $.93-1.46$ & .85 & $\begin{array}{l}.62- \\
1.16\end{array}$ & $2.34^{+*}$ & $1.32-4.15$ \\
\hline \multicolumn{8}{|l|}{$\star p<.05$} \\
\hline \multicolumn{8}{|l|}{$\star * \quad p<.01$} \\
\hline$* p<.001$ & & & & & & & \\
\hline
\end{tabular}

Table 2. Binary logistic regressions of the TEMPS-A predicting mood disorders and substance use disorders. 


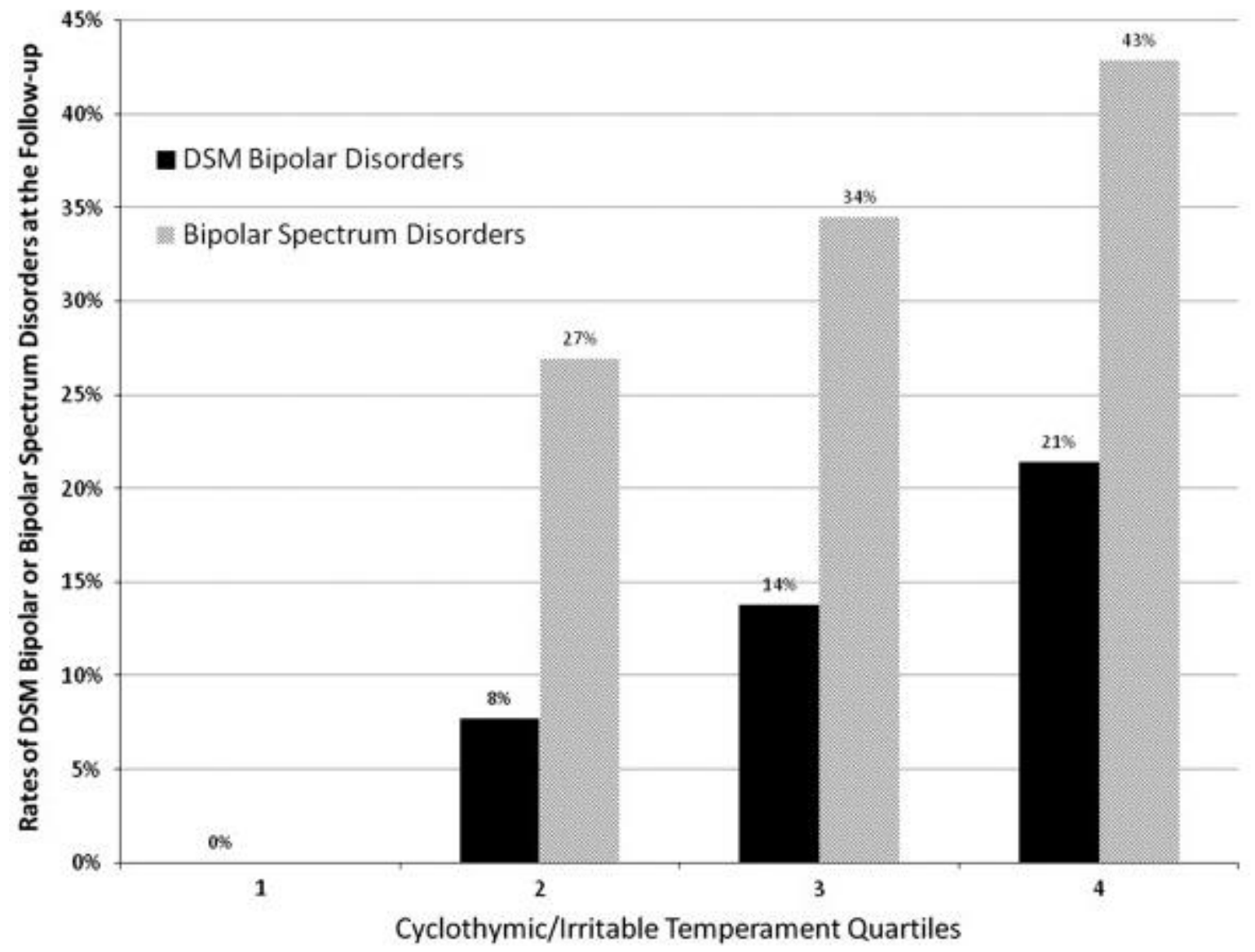

Figure 1. Percentage of bipolar spectrum disorders at the follow-up by cyclothymic/irritable temperament quartiles.

Table 3 presents the associations of affective temperaments with measures of psychopathology and impairment. Cyclothymic/irritable temperament significantly predicted interview ratings of hyperthymic temperament, impaired psychosocial functioning, and borderline personality traits. Cyclothymic/irritable temperament was also positively associated with measures of impulsivity, including impulsive-nonconformity, negative urgency, lack of premeditation, and lack of perseverance. Additionally, cyclothymic/irritable temperament was associated with heaviest alcohol use and impairment, as well as current and heaviest drug use. Overall, cyclothymic/irritable temperament had the strongest association with pathological outcomes, specifically bipolar psychopathology. 


\begin{tabular}{|c|c|c|c|c|c|}
\hline Criterion & $\begin{array}{l}\text { Mean } \\
(\mathrm{SD})\end{array}$ & Hyperthymic $\beta$ & Dysthymic $\beta$ & Cyclothymic/lmitable $\beta$ & $\begin{array}{l}\text { Total } \\
R^{2}\end{array}$ \\
\hline $\begin{array}{l}\text { Hyperthymic temperament } \\
\text { total score }\end{array}$ & $\begin{array}{l}5.89 \\
(3.85)\end{array}$ & $.641^{\cdots+}$ & .084 & $.192^{*}$ & $.385^{1+n}$ \\
\hline $\begin{array}{l}\text { GAF-Psychosocial } \\
\text { functioning }\end{array}$ & $\begin{array}{l}74.02 \\
(11.56)\end{array}$ & -.094 & -.099 & $-.379^{+1+}$ & $.166^{+1+1}$ \\
\hline $\begin{array}{l}\text { IPDE-Borderline } \\
\text { dimensional scores }\end{array}$ & $\begin{array}{l}1.50 \\
(2.21)\end{array}$ & .164 & .030 & $.521^{t+1}$ & $.273^{+1+}$ \\
\hline Impulsive-nonconformity & $\begin{array}{l}10.79 \\
(7.27)\end{array}$ & $.401^{+1+\infty}$ & .002 & $.556^{+1+t}$ & $.385^{\prime+1+}$ \\
\hline \multicolumn{6}{|l|}{ UPPS } \\
\hline Negative urgency & $2.00(.57)$ & .182 & .003 & $.505^{+1+t}$ & $.253^{m+1+}$ \\
\hline Lack of perseverance & $1.73(.45)$ & -.147 & -.087 & $.304^{+\infty}$ & $.110^{\prime \prime}$ \\
\hline Lack of premeditation & $1.88(.49)$ & $.282^{\circ}$ & -.116 & $.201^{*}$ & $.128^{+\prime}$ \\
\hline Sensation seeking & $2.81(.62)$ & $.467^{+1+}$ & .045 & .025 & $.196^{+1+\cdot}$ \\
\hline \multicolumn{6}{|l|}{ Grandiosity } \\
\hline Famous & $\begin{array}{l}1.99 \\
(1.45)\end{array}$ & $.523^{+1+}$ & -.101 & .154 & $.318^{+1+1}$ \\
\hline Ambition & $2.99(.87)$ & $.300^{\prime \prime}$ & -.097 & .084 & $.121^{\prime \prime}$ \\
\hline Odd/different & $\begin{array}{l}2.54 \\
(1.22)\end{array}$ & $.299^{\circ-}$ & -.001 & $.272^{*+}$ & $.132^{\prime+}$ \\
\hline Creative & $\begin{array}{l}2.70 \\
(1.23)\end{array}$ & $.412^{i+1}$ & .016 & -.013 & $.168^{+\cdots+}$ \\
\hline Leadership & $.69(.47)$ & $.282^{\circ+}$ & $-.333^{+1+t}$ & .038 & $.273^{+1+1}$ \\
\hline Attention & $.39(.49)$ & $.321^{t+}$ & -.103 & $.266^{+\prime}$ & $.165^{+n+}$ \\
\hline Magazine & $\begin{array}{l}1.83 \\
(1.49)\end{array}$ & $.382^{\prime+1}$ & -.099 & .025 & $.189^{+=1+}$ \\
\hline \multicolumn{6}{|l|}{ Alcohol use and impairment } \\
\hline Current alcohol use & $\begin{array}{l}3.23 \\
(3.75)\end{array}$ & .111 & -.194 & .010 & $.070^{\prime}$ \\
\hline Heaviest alcohol use & $\begin{array}{l}7.47 \\
(6.73)\end{array}$ & $.241^{*}$ & -.169 & $.228^{\prime}$ & $.130^{+\prime}$ \\
\hline Current alcohol impairment & $.79(.63)$ & $.263^{\circ}$ & -.073 & .160 & $.095^{\circ}$ \\
\hline $\begin{array}{l}\text { Heaviest alcohol } \\
\text { impairment }\end{array}$ & $\begin{array}{l}1.29 \\
(1.04)\end{array}$ & $.352^{+1+t}$ & -.077 & $.326^{t+1+}$ & $.201^{+\cdots+1}$ \\
\hline \multicolumn{6}{|l|}{ Drug use and impairment } \\
\hline Current drug use & $.67(1.80)$ & .047 & $-.276^{\prime}$ & $.217^{*}$ & $.091^{*}$ \\
\hline Heaviest drug use & $\begin{array}{l}3.04 \\
(5.48)\end{array}$ & .098 & -.215 & $.210^{\circ}$ & $.080^{\circ}$ \\
\hline Current drug impairment & $.29(.72)$ & .174 & -.141 & .082 & .088 \\
\hline Heaviest drug impairment & $.90(1.22)$ & .142 & -.131 & .168 & .050 \\
\hline \multicolumn{6}{|l|}{$p<.05$} \\
\hline * p<.01. & & & & & \\
\hline
\end{tabular}

Table 3. Linear regressions of the TEMPS-A predicting continuous measures of psychopathology and impairment.

As hypothesized, hyperthymic temperament predicted interview ratings of hyperthymic temperament and all measures of grandiosity. As expected, only lack of premeditation and sensation seeking were significantly associated with hyperthymic temperament. Hyperthymic 
temperament was positively associated with lifetime heaviest alcohol use as well as current and heaviest impairment. Dysthymic temperament was only associated with current drug use and the leadership measure of grandiosity in a negative direction.

In response to a reviewer's recommendation, we examined whether the interaction of cyclothymic/irritable and dysthymic temperament accounted for variance in mood psychopathology, over-and-above the main effects. However, the interaction term was not significant in the prediction of DSM bipolar disorders, broad bipolar spectrum disorders, major depressive episodes, or major depressive disorders.

\section{Discussion}

The present study examined the construct validity of affective temperaments, as assessed by the TEMPS-A, with respect to longitudinal prediction of mood psychopathology. Few studies have examined the relationship between affective temperaments and bipolar psychopathology in nonclinically ascertained samples and this is the first study to our knowledge to assess the predictive validity of affective temperaments. The present study aimed to fill the gap in the literature by examining the extent to which affective temperaments predicted bipolar spectrum psychopathology and impairment in a three-year longitudinal sample of young adults at-risk for bipolar disorders.

Consistent with previous literature (Di Florio et al., 2010 and Evans et al., 2005), cyclothymic/irritable temperament predicted DSM-IV-TR bipolar disorders, broader bipolar spectrum disorders, major depressive episodes, and hypomania over the three-year follow-up. Cyclothymic/irritable temperament did not predict unipolar major depressive disorder consistent with the notion that cyclothymic/irritable temperament is uniquely associated with risk for bipolar, not unipolar, mood psychopathology. Cyclothymic/irritable temperament also predicted new cases of broader bipolar spectrum disorders, but not DSM-IV-TR bipolar disorders, suggesting that affective temperaments could serve as a way to better identify those who experience subthreshold symptoms and are at risk for developing clinical bipolar disorders.

Cyclothymic/irritable temperament also predicted impaired psychosocial functioning, borderline personality traits, and impulsivity and was associated with an overall pattern of impairment and psychopathology relative to the other temperaments. Akiskal's (2004) model of bipolar spectrum psychopathology better captures these individuals who may not only be at risk for developing full-blown disorders, but also experiencing significant impairment. This broader diagnostic model may be useful as an alternative to more stringent diagnostic criteria to more efficiently identify those experiencing subthreshold mood symptoms and impairment.

Among the affective temperaments, cyclothymic/irritable temperament conveyed the greatest risk for psychopathology and impairment. It was uniformly associated with symptoms, disorders, and impairment, whereas hyperthymic temperament (consistent with its original formulation) captured both adaptive and maladaptive characteristics. Hyperthymic temperament significantly predicted broader bipolar spectrum disorders, and history of hypomania or interview-rated hyperthymic temperament. Consistent with previous research (Evans et al., 2005 and Mendlowicz et al., 2005; Nowakowska et al., 2005), it was not associated with more severe 
outcomes such as DSM-IV-TR bipolar disorders and mood disorders. Strikingly, hyperthymic temperament was associated with a decreased likelihood of DSM-IV-TR depressive disorder, suggesting that the temperament serves as a measure of risk for bipolar spectrum psychopathology, not simply broad risk for mood disorders. As hypothesized, hyperthymic temperament significantly predicted interview ratings of hyperthymic temperament characteristics, grandiose traits, along with measures of impulsivity. Hyperthymic temperament significantly predicted all measures of grandiosity, which is consistent with the adaptive qualities of confidence and optimism imbedded within the temperament, as well as the grandiose characteristics of the temperament. Similar results were reported in Iasevoli et al. (2013) who found that hyperthymic temperament acted as a protective factor against symptoms of depression in a clinically ascertained sample of mood disorder patients. Though hyperthymic temperament includes some maladaptive characteristics (e.g., risk-taking, over-involvement), the results of the present study suggest hyperthymic temperament may provide resilience against functional impairment and clinical mood psychopathology — although continued longitudinal assessment is needed to determine if this continues across time.

Differential patterns emerged in terms of the four facets of impulsivity in relation to cyclothymic/irritable temperament and hyperthymic temperament. Specifically, cyclothymic/irritable temperament was significantly associated with negative urgency and lack of perseverance, and modestly associated with lack of premeditation, and was unassociated with sensation seeking. Negative urgency, which is strongly associated with neuroticism, involves impulsive behaviors in response to negative affect. The chronic shifts in moods characteristic of cyclothymic/irritable temperament impede individuals from focusing on tasks at hand and contribute to reckless behavior that occurs in reaction to negative arousal. Hyperthymic temperament was positively associated with sensation seeking and lack of premeditation, and was unassociated with negative urgency or lack of perseverance. In comparison to impulsivity experienced in cyclothymic/irritable temperament, hyperthymic temperament captures the thrill seeking component of impulsivity and is generally unassociated with negative affect. These specific facets of impulsivity reflect upon the reckless and over-confident nature of hyperthymic temperament that can lead to maladaptive outcomes.

Contrary to hypotheses, dysthymic temperament was not associated with any measures of psychopathology or impairment - including measures of clinical depression. Furthermore, the interaction of dysthymic and cyclothymic/irritable temperament did not predict mood disorders. Dysthymic temperament significantly predicted the leadership measure of grandiosity (in an inverse direction) consistent with the non-assertive and self-critical qualities of the temperament. The null results for dysthymic temperament are consistent with the lack of cross-sectional findings for this scale in this sample; however, it may be that the duration of the study has been too short to observe the effects of dysthymic temperament. The present non-significant results, along with Walsh et al. (2012a) findings, are contrary to Akiskal's (2004) original formulation. This raises some concern with respect to the validity of Akiskal's model or specifically the extent to which the dysthymic temperament subscale of the TEMPS-A adequately measures the construct it purports to measure. There is some reason to suspect the latter. The dysthymic subscale is the shortest of the four temperament scales and has the poorest reliability. Furthermore, the items do not seem to comprehensively cover the domain (provide content validity) as well as the other temperament subscales. Note that we have used the 50-item 
research version of the TEMPS-A and findings for dysthymic temperament may be found with the 100-item clinical version. Refinement of the subscale may be needed to make a clearer determination of the validity of this temperament.

In addition to the limits mentioned above with regard to dysthymic temperament, there are several other limitations of note. The TEMPS-A was only administered at the cross-sectional assessment and we did not examine stability of these ratings across the two assessments. However, previous research (Akiskal et al., 2005a) has established the test-retest reliability of the measure and the focus of our study was on the predictive validity of affective temperaments, not the reliability of the scale. A comprehensive assessment of family history of psychopathology and mental health treatment was not collected in the present study. Detailed information regarding mental health treatment could offer greater understanding of the costs and impairment associated with bipolar disorders. The study focused on impairment and psychopathologytherefore, we did not obtain detailed information about adaptive expressions of affective temperaments (especially hyperthymic temperament). Distinguishing between adaptive and maladaptive expression of hyperthymic temperament could provide important information regarding risk and resilience factors. Additionally, the sample used in the present study is still relatively young and has not yet reached the peak age of onset for the development of clinical disorders. Further follow-up could provide a more comprehensive look into the development and progression of mood psychopathology over a longer time interval.

Overall, the present study provides support for the construct of affective temperaments, as measured by the TEMPS-A, and their relationship to bipolar psychopathology. Additionally, the present research was unique in that it assessed the predictive validity of affective temperaments with respect to mood psychopathology and impairment at a three-year longitudinal follow-up assessment. To our knowledge, this is the first study of its kind. Future study of affective temperaments could enhance understanding of the development of bipolar disorders and aid in the identification of those at risk for bipolar psychopathology.

\section{Elsevier funding body agreements and policies}

This research was supported by an award from the American Psychological Foundation Council and the Graduate Departments of Psychology (APF/COGDOP) to Molly Walsh and an award from the UNCG College of Arts \& Sciences Proposal Preparation Program to Thomas Kwapil. Neus Barrantes-Vidal is supported by the Academia Research Award (Institució Catalana de Recerca i Estudis Avançats; ICREA) from the Catalan Government.

\section{Conflict of interest}

None of the authors had any conflicts of interest.

\section{Acknowledgements}

The authors thank Georgina Gross and Charlotte Chun for their comments on the manuscript.

\section{References}


Akiskal, H.S., 2004. The bipolar spectrum in psychiatry and general medical practice. Prim. Psychiatry 11, 30-35.

Akiskal, H.S., Akiskal, K.K., Haykal, R.F., Manning, J.S., Connor, P.D., 2005a. TEMPS-A: progress towards validation of a self-rated clinical version of the Temperament Evaluation of the Memphis, Pisa, Paris, and San Diego Autoquestionnaire. J. Affect. Disord. 85, 3-16.

Akiskal, H.S., Bourgeois, M.L., Angst, J., Post, R., Moller, H., Hirschfeld, R., 2000. Reevaluating the prevalence of and diagnostic composition within the broad clinical spectrum of bipolar disorders. J. Affect. Disord. 59 (Suppl. 1), 5-30.

Akiskal, H.S., Akiskal, H.S., Khani, M.K., Scott-Strauss, A., 1979. Cyclothymic temperamental disorders. Psychiatr. Clin. North Am. 2, 527-554.

Akiskal, H.S., Mallya, G., 1987. Criteria for the "soft" bipolar spectrum: treatment implications. Psychopharmacol. Bull. 23, 68-73.

Akiskal, H.S., Mendlowicz, M.V., Jean-Louis, G., Rapaport, M.H., Kelsoe, J.R., Gillin, J.C., Smith, T.L., 2005b. TEMPS-A: validation of a short version of a self-rated instrument designed to measure variations in temperament. J. Affect. Disord. 85, 45-52.

Akiskal, H.S., Pinto, O., 1999. The evolving bipolar spectrum. Prototypes I, II, III, and IV. Psychiatr. Clin. North Am. 22, 517-534.

Angst, J., Gamma, A., Benazzi, F., Ajdacic, V., Eich, D., Rossler, W., 2003. Toward a redefinition of subthreshold bipolarity: epidemiology and proposed criteria for bipolar II, minor bipolar disorders and hypomania. J. Affect. Disord. 73, 133-146.

American Psychiatric Association, 2000. Diagnostic and statistical manual of mental disorders, fourth ed. American Psychiatric Association, Washington, DC (text revision).

Borkowska, A., Rybakowski, J., Drozdz, W., Bielinski, M., Kosmowska, M., RajewskaRager, A., Bucinski, A., Akiskal, K., Akiskal, H., 2010. Polish validation of the TEMPS-A: the profile of affective temperaments in a college student population. J. Affect. Disord. 123, 36-41.

Chapman, L.J., Chapman, J.P., Numbers, J.S., Edell, W.S., Carpenter, B.N., Beckfield, D., 1984. Impulsive nonconformity as a trait contributing to the prediction of psychotic-like and schizotypal symptoms. J. Nerv. Ment. Dis. 172, 681-691.

Di Florio, A., Hamshere, M., Forty, L., Green, E.K., Grozeva, D., Jones, I., Caesar, S., Fraser, C., Gordon-Smith, K., Jones, L., Craddock, N., Smith, D.J., 2010. Affective temperaments across the bipolar-unipolar spectrum: examination of the TEMPS-A in 927 patients and controls. J. Affect. Disord. 123, 42-51.

Eckblad, M., Chapman, L., 1986. Development and validation of a scale for hypomanic personality. J. Abnorm. Psychol. 95, 214-222.

Evans, L., Akiskal, H.S., Keck Jr., P.E., Mcelroy, S.L., Sadovnick, A.D., Remick, R.A., Kelsoe, J.R., 2005. Familiality of temperament in bipolar disorder: support for a genetic spectrum. J. Affect. Disord. 85, 153-168.

First, M., Spitzer, R., Gibbon, M., Williams, J., 1995. Structured Clinical Interview for DSM-IV Axis I disorders (SCID-I/P, Version 2.0). Biometric Research Department, New York.

Ghaemi, S., Ko, J.Y., Goodwin, F.K., 2002. 'Cade's disease' and beyond: misdiagnosis, antidepressant use, and a proposed definition for bipolar spectrum disorder. Can. J. Psychiatry 47, 125-134.

Hinic, D., Akiskal, S., Akiskal, K., Jovic, J., Ignjatovic Ristic, D., 2013. Validation of the Temps-A in university student population in Serbia. J. Affect. Disord. 149, 146-151. 
Iasevoli, F., Valchera, A., Di Giovambattista, E., Marconi, M., Rapagnani, M., De Berardis, D., Martinotti, G., Fornaro, M., Mazza, M, Tomasetti, C., Buonaguro, E., Di Giannantonio, M., Perugi, G., de Bartolomeis, A., 2013. Affective temperaments are associated with specific clusters of symptoms and psychopathology: a cross-sectional study on bipolar disorder inpatients in acute manic, mixed, or depressive relapse. J. Affect. Disord. 151, 540-550.

Judd, L.L., Akiskal, H.S., 2003. The prevalence and disability of bipolar spectrum disorders in the US population: re-analysis of the ECA database taking into account subthreshold cases. J. Affect. Disord. 73, 123-131.

Judd, L.L., Akiskal, H.S., Schettler, P.J., Endicott, J., Leon, A.C., Solomon, D.A., Coryel, W., Maser, J.D., Keller, M.B., 2005. Psychosocial disability in the course of bipolar I and II disorders: a prospective, comparative, longitudinal study. Arch. Gen. Psychiatry 62, $1322-1330$.

Klerman, G.L., 1987. The classification of bipolar disorders. Psychiatr. Ann. 17, 13-17.

Kraeplin, E., 1899/1921. Manic-depressive Insanity and Paranoia. E. \& S. Livingstone, Edinburgh ([trans]).

Kwapil, T.R., 1996. A longitudinal study of drug and alcohol use by psychosis-prone and impulsive-nonconforming individuals. J. Abnorm. Psychol. 105, 114-123.

Loranger, A., Sartorius, N., Andreoli, A., Berger, P., Buchheim, P., Channabasavanna, S., Coid, B., Dahl, A., Diekstra, F.W., Ferguson, B., Jacobsberg, L.B., Mombour, W., Pull, C., Ono, Y., Regier, D.A., 1994. The international personality disorder examination: the World Health Organization/alcohol, drug abuse, and Mental Health Administration international pilot study of personality disorders. Arch. Gen. Psychiatry 51, 215-224.

Mendlowicz, M.V., Jean-Louis, G., Kelsoe, J.R., Akiskal, H.S., 2005. A comparison of recovered bipolar patients, healthy relatives of bipolar probands, and normal controls using the short TEMPS-A. J. Affect. Disord. 85, 147-151.

Nilsson, K., Straarup, K., Jørgensen, C., Licht, R., 2012. 'Affective temperaments' relation to functional impairment and affective recurrences in bipolar disorder patients. J. Affect. Disord. 138, 332-336.

Nowakowska, C., Strong, C.M., Santosa, C.M., Wang, P.W., Ketter, T.A., 2005. Temperamental commonalities and differences in euthymic mood disorder patients, creative controls, and healthy controls. J. Affect. Disord. 85, 207-215.

Ösby, U., Brandt, L., Correia, N., Ekbom, A., Sparén, P., 2001. Excess mortality in bipolar and unipolar disorder in Sweden. Arch. Gen. Psychiatry 58, 844-850.

Perroud, N., Baud, P., Mouthon, D., Courtet, P., Malafosse, A., 2011. Impulsivity, aggression and suicidal behavior in unipolar and bipolar disorders. J. Affect. Disord. 134, 112-118.

Rózsa, S., Rihmer, Z., Gonda, X., Szili, I., Rihmer, A., Kö, N., Németh, A., Pestality, P., Bagdy, G., Alhassoon, O., Akiskal, K.K., Akiskal, H.S., 2008. A study of affective temperaments in Hungary: internal consistency and concurrent validity of the TEMPS-A against the TCI and NEO-PI-R. J. Affect. Disord. 106, 45-53.

Signoretta, S., Maremmani, I., Liguori, A., Perugi, G., Akiskal, H.S., 2005. Affective temperament traits measured by TEMPS-I and emotional-behavioral problems in clinically-well children, adolescents, and adults. J. Affect. Disord. 85, 169-180.

Walsh, M.A., Brown, L.H., Barrantes-Vidal, N., Kwapil, T.R., 2013. The expression of affective temperaments in daily life. J. Affect. Disord. 145, 179-186. 
Walsh, M.A., Royal, A., Barrantes-Vidal, N., Kwapil, T.R., 2012a. The association of affective temperaments with impairment and psychopathology in a young adult sample. J. Affect. Disord. 141, 373-381.

Walsh, M.A., Royal, A.M., Brown, L.H., Barrantes-Vidal, N., Kwapil, T.R., 2012b. Looking for bipolar spectrum psychopathology: identification and expression in daily life. Compr. Psychiatry 53, 409-421.

Whiteside, S.P., Lynam, D.R., Miller, J.D., Reynolds, S.K., 2005. Validation of the UPPS impulsive behaviour scale: a four-factor model of impulsivity. Eur. J. Pers. 19, 559-574. 